\title{
CORRELATING THE POLLENS GATHERED BY APIS MELLIFERA WITH THE LANDSCAPE FEATURES IN WESTERN FRANCE
}

\author{
PIROUX ${ }^{1}$, M. - LAMBERT ${ }^{1 *}$, O. - PUYO ${ }^{1}$, S. - FARRERA ${ }^{2}$, I. - THORIN ${ }^{3}$, C. - L'HOSTIS ${ }^{1}$, \\ M. - VIGUES ${ }^{4,5}$, B. - BASTIAN $^{6,7}$, S. \\ ${ }^{1}$ LUNAM Université, Oniris, Ecole Nationale Vétérinaire, Agroalimentaire et de l'Alimentation \\ Nantes-Atlantique, Plateforme Environnementale Vétérinaire, Centre Vétérinaire de la Faune \\ Sauvage et des Ecosystèmes des Pays de la Loire (CVFSE), \\ Atlanpole-La Chantrerie, CS40706, Nantes, F-44307, France \\ (phone: $+33(0) 2406877$ 76)
}

${ }^{2}$ Montpellier SupAgro Unité d'Expertise 3P « Phytoprotection, Pathologie des abeilles, Palynologie »,

Domaine de la Valette, 900 rue JF Breton, Montpellier, F-34090, France

${ }^{3}$ LUNAM Université, Oniris, Ecole Nationale Vétérinaire, Agroalimentaire et de l'Alimentation Nantes-Atlantique, Unité de Statistiques, Atlanpole-La Chantrerie, CS40706, Nantes, F-44307, France

${ }^{4}$ Clermont Université, Université Blaise Pascal, Laboratoire « Microorganismes: Génome et Environnement », BP10448, Clermont-Ferrand, F-63000, France

${ }^{5} \mathrm{CNRS}, \mathrm{UMR}$ 6023, LMGE, 24 Avenue des Landais, BP 80026, Aubière, F-63171, France

${ }^{6}$ LUNAM Université, Oniris, Ecole Nationale Vétérinaire, Agroalimentaire et de l'Alimentation Nantes-Atlantique, UMR1300 Biologie, Epidémiologie et Analyse de Risque en Santé animale, Atlanpole-La Chantrerie, CS40706, Nantes, F-44307, France

\author{
${ }^{7}$ INRA, UMR1300, \\ Nantes, F-44307, France \\ *Corresponding author \\ e-mail: olivier.lambert@oniris-nantes.fr
}

(Received $26^{\text {th }}$ Sep $2013 ;$ accepted $22^{\text {nd }}$ July 2014 )

\begin{abstract}
Honey bee health depends on various factors, including the availability of food resources and chronic exposure to toxins in the foraging area. These parameters can be evaluated using indicators based on either pollen gathered to the hive or landscape features of the foraging area, including the structure, land use, or density of such specific landscape elements as hedgerows. This study examines the correlation between the diversity of pollens gathered and the landscape features in a 3-km radius using Geographic Information System technology. Palynological analyses were performed on pollen pellets collected from sixteen apiaries in western France during one year. Richness, diversity and similarity indices were calculated for land-cover features and palynological data and then compared. The land-cover analyses permitted the identification of three different landscape contexts (hedgerow, cultivated, and urban landscapes). Although the palynological profiles were highly diverse, some taxa were conserved between hives. The flower richness was greater in the apiaries from urban landscapes than in apiaries from rural landscapes, regardless of the dominant land-cover. The statistical analysis did not associate a specific flora with a specific landscape. However, it was possible to distinguish the pollen gathered by bees in urban landscapes and from pollen collected in rural areas.
\end{abstract}


Keywords: foraging area, land-cover, palynology, honey bees

\section{Introduction}

Profound changes in urban and farming landscapes have occurred over the last decade, and the increasing human population has led to expanding urbanization and modifications to urban and suburban landscapes (Loibl and Toetzer, 2002). Similarly, profound changes in agricultural practices induced by agricultural production methods, technological advances and government policies, have modified the landscape structure and composition (Burel and Baudry, 1990; Macdonald and Johnson, 2000; Robinson and Sutherland, 2002; Le Féon et al., 2010). This agricultural intensification has affected land-use patterns, resulting in 1) a large increase in cultivated areas, 2) fragmentation of uncultivated features including forests, hedgerows (Burel and Baudry, 1999), and natural meadows (Monteiro et al., 2011), and 3) the loss of these seminatural elements (Agger and Brandt, 1988; Hobbs et al., 2008). Furthermore, the decrease in landscape heterogeneity has contributed to the decline of biodiversity (McLaughlin and Mineau, 1995; Krebs et al., 1999; Holzschuh et al., 2007; Le Féon et al., 2010; Potts en al., 2010) through the loss of suitable habitats and food resources for many species of wild flora and fauna (Robinson and Sutherland, 2002; Benton et al., 2003; Carvell et al., 2007; Hannon and Sisk, 2009).

The composition and structure of the landscape have strong effects on honey bees, particularly with regard to the pollen collected and the abundance of flower-visiting bees (Steffan-Dewenter et al., 2002; Steffan-Dewenter and Kuhn, 2003). Fragmentation has an impact on the distribution of plants and the distribution of animals in relation to the modification of patch size, edges, and landscape connectivity (Hadley and Betts, 2012), and the loss of habitat decreases the plant density and has a negative impact on the abundance of pollinators (Hadley and Betts, 2012). In fact, flower richness and abundance are important for the food balance of honey bees and thus for the health of the colony (Crailsheim et al. 1992; Alaux et al. 2010). Furthermore, environmental pollution in landscape contaminates bees and beehive products (Balayiannis and Balayiannis, 2008; Perugini et al., 2009; Lambert et al. 2012).

The qualification of the landscape context is therefore important to predict the food resources and toxic exposure of honey bee colonies. However, the extent to which the pollen collected around an apiary is correlated to the surrounding landscape composition and thus with the landscape context remains questionable. As an example, apiaries surrounded by high-intensity agriculture and isolated from semi-natural habitats are expected to exhibit a lower floral diversity in the collected pollen, whereas apiaries in proximity to greater proportions of urban habitats could have higher levels of floral diversity represented in the pollen stores, as related to the variety of urban ornamental species. In an attempt to address these questions, the landscape variables of a foraging area and palynological data were compared in an array of 16 apiaries within different landscape contexts. The results are discussed with respect to the particular landscape components, cultural practices and/or selective foraging that could have an impact on the diversity of the pollen returned to the apiaries. 


\section{Materials and Methods}

\section{Study area}

Sixteen apiaries owned by sixteen different volunteer beekeepers were selected for this study. The apiaries, indicated by a letter (A to P), were located in six departments in western France (Fig. 1): nine apiaries in Loire-Atlantique (44, France), two in Vendée (85, France), two in Maine et Loire (49, France), two in Sarthe (72, France), one in Mayenne (53, France).

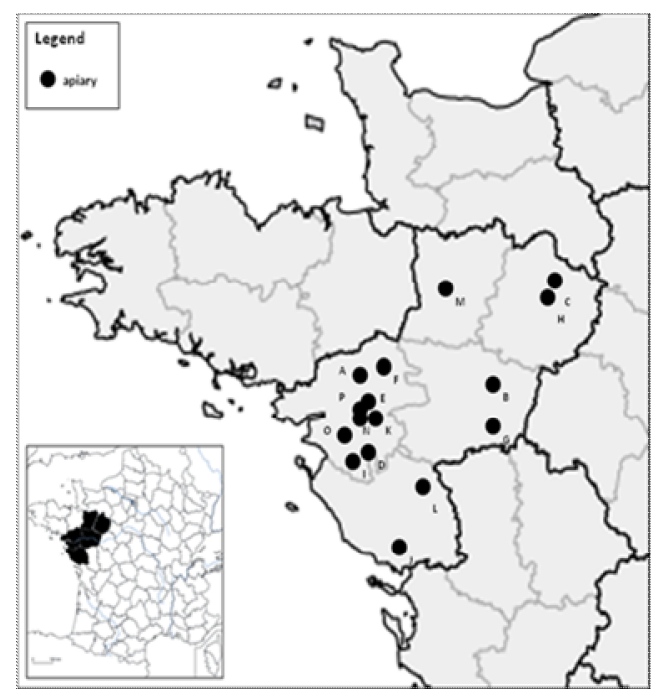

Figure 1. Location of the sixteen apiaries.

The foraging distance depends on landscape structure and food resources (Beekman and Ratnieks, 2000; Steffan-Dewenter and Kuhn, 2003) and can reach 13.5-km (to collect nectar) (Visscher et al., 1996). Nevertheless, the average foraging distance varies between 1.5-km (Steffan-Dewenter and Kuhn, 2003) and $6.1 \mathrm{~km}$ (Beekman and Ratnieks, 2000), with resources near the beehives being favored. As a compromise between the highest values and the average of foraging distance, a radius of 3 kilometers was chosen for the foraging area (2827 ha) in the present study.

\section{Landscape analysis}

The land-cover data used for the analysis was obtained from the European data base Corine Land Cover (2006) for the categories urban areas, woodland, and water. The identification system for agricultural plots from the Common Agricultural Policy of Europe (2008) was used for the cultivated areas of annual crops and permanent and market garden crops and grassland. Missing land-use data for agriculture were complemented by a field survey (a direct questionnaire and visit to the farmers in the foraging areas). The hedgerow networks and copses were digitized manually on the basis of satellite pictures (BD Ortho ${ }^{\circledR}$ IGN, 2004) using ArcGis 9.2. The areas, hedgerow density, and average plot size were calculated using ArcGis 9.2.

The fourteen synthetic variables describing land-use were chosen by aggregating more detailed categories (Table 1 and Appendix A). The objective was to retain sufficient details to discriminate among the different landscape types. 
Table 1. Description of the variables (*Declarative data for 2008 of the agricultural parcel identification system of Council Regulation (EC) $N^{\circ}$ 1593/2000 of 17 July 2000; †Annual crops).

\begin{tabular}{|c|c|c|c|}
\hline Variables & Description & Source & Units \\
\hline Grassland & natural meadows, temporary meadows & $*$ & ha \\
\hline Fallow land & fallow land & * & ha \\
\hline Forage crops $\dagger$ & forage, broad bean, pea & * & ha \\
\hline Grain crops $\dagger$ & oat, wheat, maize, barley, rye & * & ha \\
\hline $\begin{array}{l}\text { Oleaginous } \\
\text { crops }{ }^{\dagger}\end{array}$ & colza, flax, sunflower & * & ha \\
\hline $\begin{array}{l}\text { Permanent } \\
\text { crops }\end{array}$ & vineyard, orchard & * & ha \\
\hline Market gardens & fruit, vegetable, aromatic plant & * & ha \\
\hline Other crops $\dagger$ & buckwheat, hemp, tobacco & * & ha \\
\hline $\begin{array}{l}\text { Wood and } \\
\text { copse }\end{array}$ & & $\begin{array}{l}\text { Corine Land Cover } 2006 \\
\text { Digitized on BD ORTHO® IGN (2004) }\end{array}$ & ha \\
\hline Urban area & urban infrastructure, airport & Corine Land Cover 2006 & ha \\
\hline Water & & Corine Land Cover 2006 (51.1/51.2) & ha \\
\hline Others & $\begin{array}{l}\text { other utilization declared, no agricultural use, } \\
\text { area not determined }\end{array}$ & * & ha \\
\hline Hedge & & Digitized on BD ORTHO® IGN (2004) & $\mathrm{m} / \mathrm{ha}$ \\
\hline $\begin{array}{l}\text { Average plot } \\
\text { size }\end{array}$ & & Field survey among farmers in the foraging area & ha \\
\hline
\end{tabular}

\section{Pollen sampling and analysis}

The pollen pellets were collected from eight colonies in each apiary in 2008. The samples were collected four times during the apicultural season: at the onset of beehive activity after wintering (Period 1: end of April - beginning of May); at the beginning of honey foraging (Period 2: beginning of June - end of July); during the middle-end stage of honey foraging (Period 3: end of July - beginning of August) and during over wintering preparation (Period 4: end of September - beginning of October).

The samples were collected in pollen trap set up by the beekeepers three days before the sample was removed. The field-collected samples were placed immediately on ice and stored in a standard freezer at $-20^{\circ} \mathrm{C}$ until analysis.

The palynological analyses of the pollen pellets were performed by the Unite de Palynologie from Montpellier SupAgro using the method of Cour (Patent CNRSANVAR, Cour, 1974) in accordance with the European method (Von der Ohe et al., 2004). For this study, the raw data were processed at the taxonomic level of the plant family. 


\section{Data analysis}

According to the experimental design, two datasets have been constituted: one for the landscape data and one for the pollen data. The statistical analysis managed to explore and compare the diversity of those datasets. In a first description stage, the richness and index of diversity were evaluated for species from the plant family (pollen) and for landscape from the land-cover data. Indices of diversity were calculated using Shannon's formula:

$$
H_{s}=-\sum p_{i} \ln \left(p_{i}\right)
$$

where (i) refers to a species and $p_{i}=\frac{n_{i}}{N}$ with $n_{i}$ being the number of individual species and $\mathrm{N}$ the overall number of individuals for all species. The Shannon indices of species on one hand and landscape in other hand were compared with a Spearman's test.

In a second description stage, the indices of similarity, Brain-Curtis index, were calculated for each data set. Then, dendrograms were generated illustrating the similarity of the apiaries for species and for landscape. The comparison of those similarity matrices was achieved by a Mantel's test performed with 5000 randomizations.

In a third description stage, a multivariate method as Canonical Correlation Analysis (CCA) was used to analyse simultaneously the plant family profiles in the pollen pellets and the land-cover features. This method explores the sample correlation between two sets of quantitative variables observed on the same experimental units (Ter Braak and Verdonschot, 1995; Gonzales et al., 2008).

The statistical analysis were performed with $\mathrm{R}$ software $(\mathrm{R} 2.12$, R development Core Team, 2011) using the "Vegan" package for factor analysis.

\section{Results}

\section{Landscape data}

Table 2 and figure 2 show the composition and structure of the sixteen foraging areas.

Table 2. Characteristics of the sixteen apiary foraging areas: composition (grassland, fallow land, forage crops, gain crops, oleaginous crops, permanent crops, market gardens, other crops, wood and copse, urban, water and others) and structure (hedgerow density and average plot size).

\begin{tabular}{l|c|c|c|c|c|c|c|c}
\hline Apiary & A & B & C & D & E & F & G & H \\
\hline Grassland (\%) & 38.1 & 12.8 & 16.2 & 21.2 & 5.7 & 45.7 & 14.3 & 19.3 \\
Fallow land (\%) & 4.0 & 5.3 & 4.2 & 6.1 & 1.0 & 3.9 & 5.7 & 6.5 \\
Forage crops (\%) & 0.9 & 0.6 & 0.6 & 0.2 & 0.0 & 0.0 & 2.7 & 1.1 \\
Grain crops (\%) & 30.5 & 47.0 & 21.6 & 31.5 & 5.0 & 31.1 & 32.9 & 37.2 \\
Oleaginous crops (\%) & 3.4 & 3.6 & 1.7 & 2.8 & 0.3 & 2.8 & 7.3 & 2.0 \\
Permanent crops (\%) & $0 . .0$ & 3.0 & 0.0 & 0.2 & 0.4 & 0.0 & 0.9 & 0.0 \\
Market gardens (\%) & 0.0 & 0.4 & 0.0 & 2.4 & 0.4 & 0.3 & 1.9 & 0.3
\end{tabular}




\begin{tabular}{|c|c|c|c|c|c|c|c|c|}
\hline Other crops (\%) & 0.0 & 0.1 & 0.0 & 0.0 & 0.0 & 0.6 & 2.1 & 0.0 \\
\hline Wood and copse $(\%)$ & 8.9 & 8.4 & 10.2 & 8.2 & 14.3 & 1.7 & 9.5 & 8.5 \\
\hline Urban area $(\%)$ & 5.7 & 7.3 & 31.6 & 0.8 & 46.9 & 4.5 & 7.4 & 2.9 \\
\hline Water (\%) & 0.0 & 0.0 & 0.0 & 0.0 & 7.0 & 0.0 & 0.0 & 0.0 \\
\hline Others (\%) & 8.4 & 11.4 & 13.9 & 26.6 & 18.9 & 9.2 & 15.2 & 22.2 \\
\hline Hedges (m/ha) & 82. & 17 & 34 & 55 & 39 & 60 & 24 & 58 \\
\hline Average area of plot (ha) & 5.1 & 4.4 & 3.8 & 4.2 & 3.1 & 5.1 & 3.3 & 3.4 \\
\hline Apiary & I & $\mathbf{J}$ & $\mathbf{K}$ & $\mathbf{L}$ & $\mathbf{M}$ & $\mathbf{N}$ & $\mathbf{O}$ & $\mathbf{P}$ \\
\hline Grassland (\%) & 32.4 & 19.9 & 0.1 & 28.9 & 42.1 & 1.5 & 45.0 & 9.6 \\
\hline Fallow land (\%) & 2.4 & 10.1 & 0.0 & 3.8 & 3.4 & 0.0 & 3.8 & 0.2 \\
\hline Forage crops (\%) & 1.3 & 0.8 & 0.0 & 1.1 & 4.8 & 0.0 & 0.9 & 0.0 \\
\hline Grain crops $(\%)$ & 25.5 & 52.5 & 0.0 & 39.4 & 37.8 & 0.6 & 30.2 & 16.7 \\
\hline Oleaginous crops (\%) & 0.7 & 2.4 & 0.0 & 6.1 & 1.3 & 0.0 & 2.0 & 0.0 \\
\hline Permanent crops (\%) & 0.0 & 0.3 & 0.0 & 0.0 & 0.0 & 0.0 & 1.3 & 0.0 \\
\hline Market gardens (\%) & 0.2 & 2.5 & 0.0 & 0.6 & 0.0 & 0.0 & 0.3 & 0.0 \\
\hline Other crops (\%) & 0.3 & 0.6 & 0.0 & 0.0 & 0.0 & 0.0 & 0.0 & 0.6 \\
\hline Wood and copse $(\%)$ & 2.1 & 3.6 & 3.5 & 8.4 & 1.9 & 5.6 & 2.7 & 14.8 \\
\hline Urban area $(\%)$ & 12.0 & 1.0 & 75.1 & 6.5 & 4.4 & 78.6 & 6.5 & 42.1 \\
\hline Water (\%) & 0.0 & 0.0 & 11.9 & 1.2 & 0.0 & 0.0 & 0.0 & 0.0 \\
\hline Others $(\%)$ &. .23 .1 & 6.4 & 9.5. & - & 4.3 & 13.7 & 7.4. & 16.1 \\
\hline Hedges (m/ha) & 69. & 35 & 13 & 33 & 59 & 18 & 87 & 45 \\
\hline Average area of plot (ha) & 2.8 & 5.1 & 2.3 & 5.1 & 4.9 & 2.5 & 3.8 & 3.4 \\
\hline
\end{tabular}

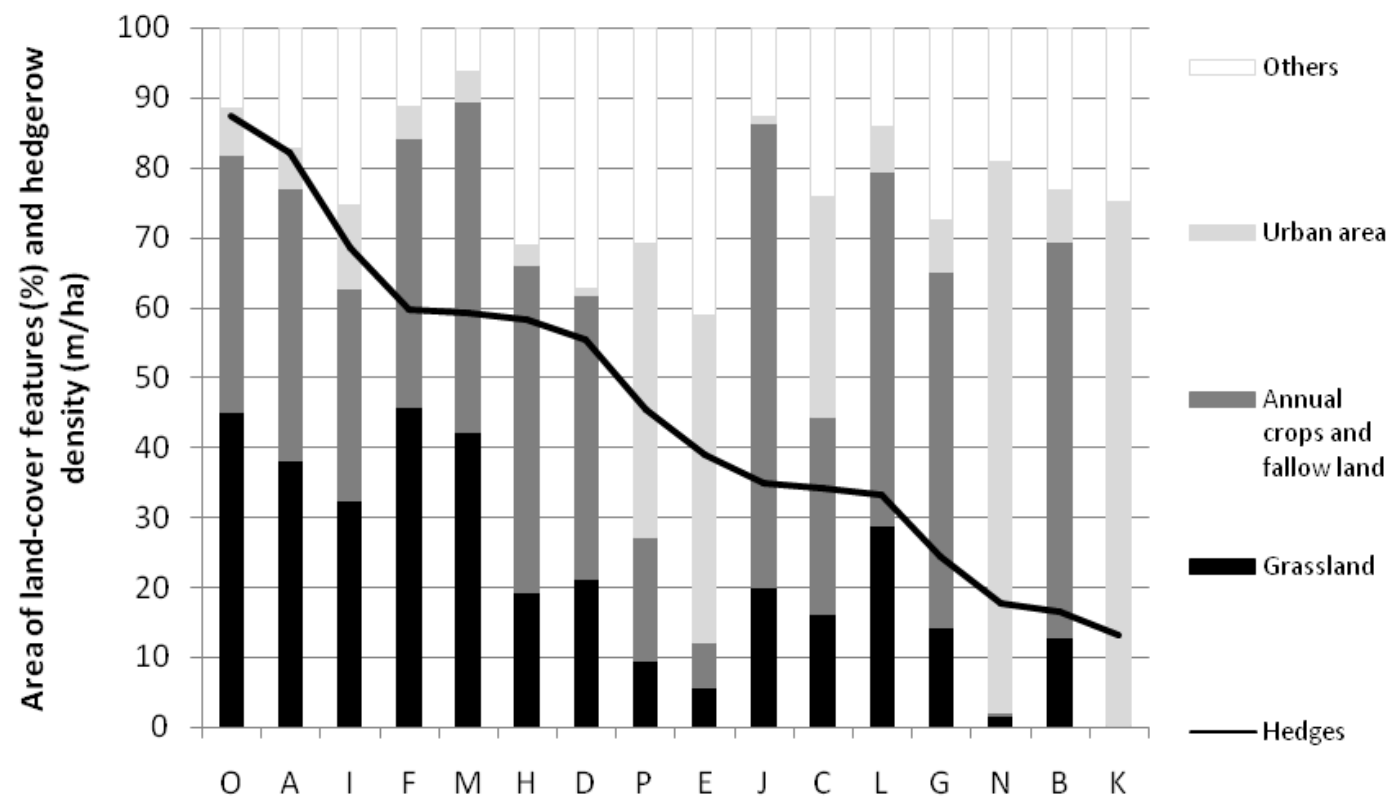

Apiaries

Figure 2. Area of land-cover features (\% of total surface) and hedgerow density $(\mathrm{m} / \mathrm{ha}$ ) of the sixteen apiary foraging areas (apiaries ranked by hedgerows density). 
For apiaries $\mathrm{N}, \mathrm{K}, \mathrm{E}$ and $\mathrm{P}, 40 \%$ of the foraging area comprised urban areas. The grasslands were dominant in foraging areas $\mathrm{F}, \mathrm{O}$, and $\mathrm{M}$, covering more than $40 \%(1000$ ha) of the entire foraging area (Table 2, Figure 2). The crops were less represented in apiaries $\mathrm{K}, \mathrm{N}, \mathrm{E}$, and $\mathrm{P}$ apiaries (less than $20 \%$ ) in contrast to the $\mathrm{J}$ and $\mathrm{B}$ sites, which contained more than 1500 ha of crops, covering more than $50 \%$ of the foraging area.

The hedgerow length comprised between 13 and $87 \mathrm{~m} /$ ha and was more important for the $\mathrm{O}, \mathrm{A}, \mathrm{I}, \mathrm{F}, \mathrm{M}, \mathrm{H}$, and D apiaries (Table 2, Figure 2). The average plot size varied between 2.3 ha $(\mathrm{K})$ and 5.1 ha $(\mathrm{A}, \mathrm{F}, \mathrm{J}$, and L), with an average of 3.6 ha and a median of 3.8 ha. Apiaries $\mathrm{C}$ and $\mathrm{O}$ were situated at the median level.

The landscape richness was more important for the $\mathrm{B}, \mathrm{G}$, and $\mathrm{J}$ apiaries (Table 3) and less important for the K, M, N, and P apiaries. The landscape diversity (Table 3) was high for apiaries $\mathrm{B}, \mathrm{C}$, and $\mathrm{G}$ and low for apiaries $\mathrm{K}, \mathrm{M}$, and $\mathrm{N}$.

Table 3. Landscape richness and diversity of the sixteen apiary foraging areas

\begin{tabular}{l|c|c|c|c|c|c|c|c|c|c|c|c|c|c|c|c}
\hline Apiary & A & B & C & D & E & F & G & H & I & J & K & L & M & N & O & P \\
\hline Landscape richness & 9 & 11 & 9 & 10 & 10 & 10 & 11 & 10 & 10 & 11 & 5 & 10 & 8 & 6 & 10 & 8 \\
\hdashline Shannon index (H) & 1.61 & 1.71 & 1.73 & 1.68 & 1.56 & 1.43 & 2 & 1.65 & 1.6 & 1.5 & 0.82 & 1.67 & 1.4 & 0.72 & 1.5 & 1.51 \\
\hline
\end{tabular}

Figure 3 shows the similarity between the land-cover of the sixteen foraging areas. The apiaries were differentiated into four groups: a first group including the K, N, E, C, and $\mathrm{P}$ apiaries, a second including the $\mathrm{J}, \mathrm{L} \mathrm{B}$, and $\mathrm{G}$ apiaries, a third including the $\mathrm{A}, \mathrm{F}$, $\mathrm{M}$, and $\mathrm{O}$ apiaries, and the last including the $\mathrm{D}, \mathrm{H}$, and I apiaries.

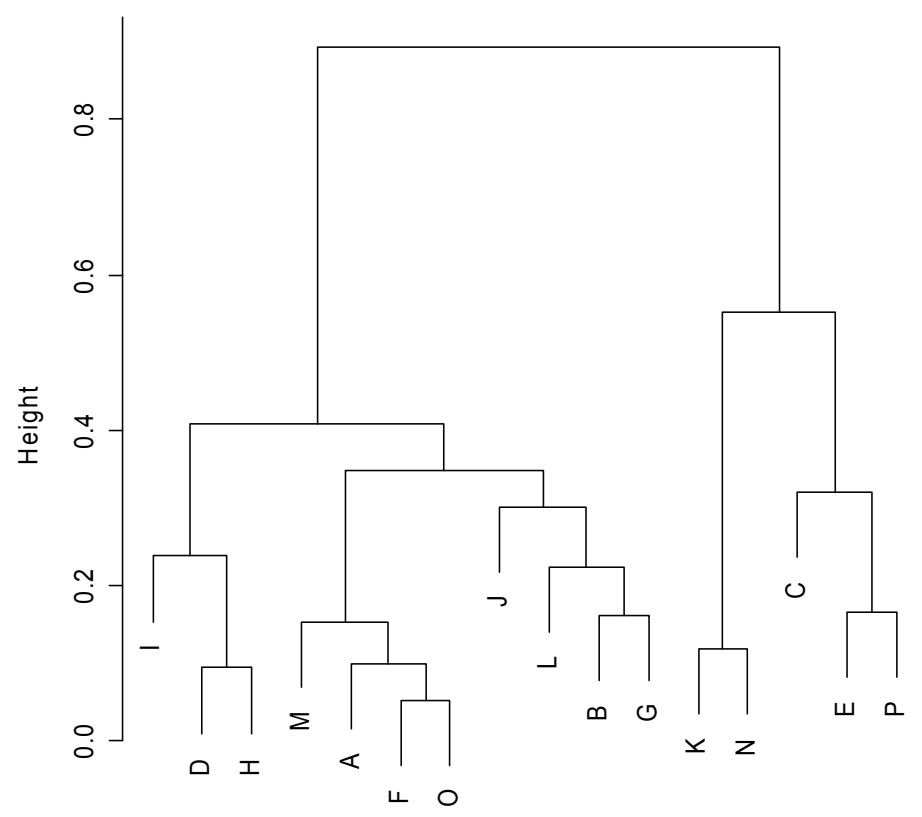

Figure 3. Dendrogram built from a similarity index (Bray-Curtis) of land-cover data of the sixteen apiary foraging areas.

\section{Palynological data}

Fifty-four families of wild and cultivated species were identified in the pollen pellets (Table 4). 
Table 4. Plant family profiles in the pollen pellets collected from sixteen apiaries (white $=$ absence of the family; black=presence of the family). The apiaries are classified according to the number of families represented in the pollen profile, from the most important to the least important. The species are classified according to their presence in the set of apiaries.

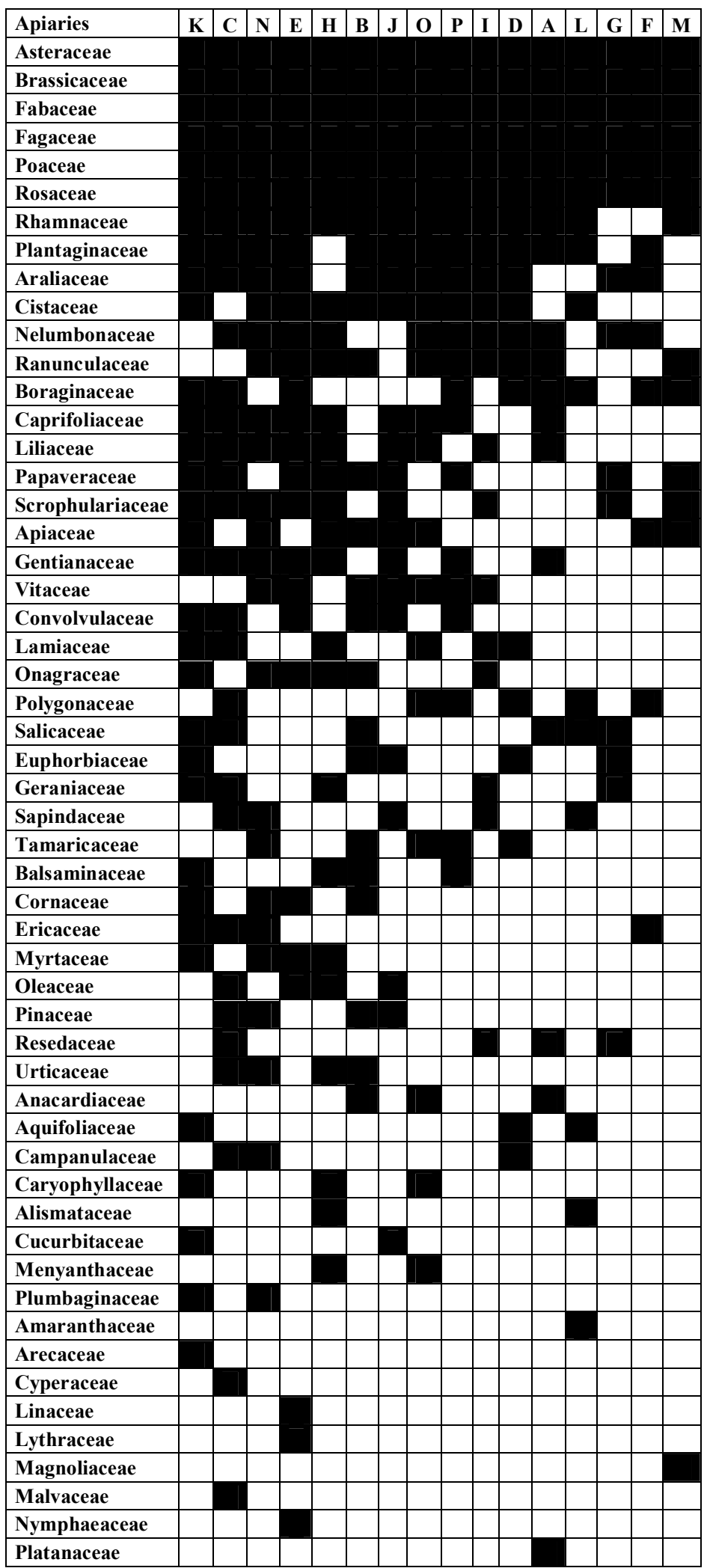


Some families were present in only one apiary (e.g., Arecaceae, Malvaceae) whereas others (i.e., Asteraceae, Brassicaceae, Fabaceae, Fagaceae, Poaceae, and Rosaceae) were present in all apiaries.

The pollen profiles of apiaries $\mathrm{K}$ and $\mathrm{C}$ had the highest richness (Table 5), in contrast to apiaries $\mathrm{F}$ and $\mathrm{M}$, with the lowest richness. The diversity index was more important for the palynological profiles of the $\mathrm{K}, \mathrm{G}$, and $\mathrm{N}$ (Table 5) apiaries, whereas the Shannon diversity index was less important for the palynological profiles of the A, E, and $\mathrm{M}$ apiaries.

Table 5. Pollen richness and diversity of the sixteen apiary foraging areas

\begin{tabular}{l|c|c|c|c|c|c|c|c|c|c|c|c|c|c|c|c}
\hline Apiaries & A & B & C & D & E & F & G & H & I & J & K & L & M & N & O & P \\
\hline Pollen richness & 18 & 24 & 30 & 19 & 27 & 13 & 14 & 26 & 20 & 23 & 31 & 16 & 13 & 28 & 22 & 21. \\
\hline $\begin{array}{l}\text { Shannon index } \\
\text { (H) }\end{array}$ & 1.48 & 1.56 & 1.57 & 1.76 & 1.51 & 1.7 & 1.98 & 1.87 & 1.87 & 1.71 & 2.19 & 1.58 & 1.51 & 1.89 & 1.54 & 1.78
\end{tabular}

Figure 4 shows the similarity between the pollen species data of the sixteen foraging areas. In contrast to the dendrogram achieved using the land-cover data, no apiary groups were identified.

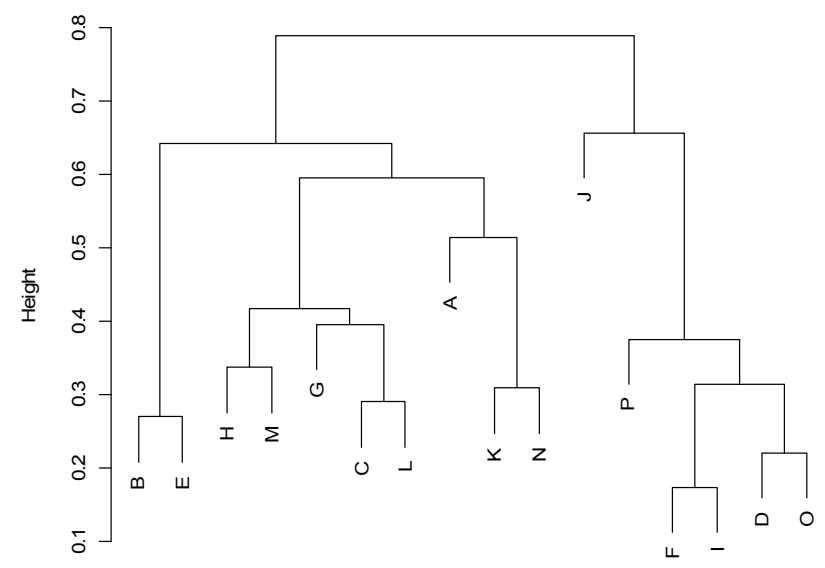

Figure 4. Dendrogram built from a similarity index (Bray-Curtis) of pollen species data of the sixteen foraging areas.

\section{Pollen and landscape}

The landscape richness and the pollen richness were different among the apiaries or within the same apiary. In general, the foraging areas with a low landscape richness presented a high pollen richness and vice versa. The landscape richness of foraging area $\mathrm{K}$ was equal to 5 , which corresponded to the lowest landscape richness, though the pollen richness was equal to 31 , which corresponded to the highest pollen richness. In contrast, the landscape richness of foraging area $\mathrm{G}$ was 11 , and the pollen richness was 14. The foraging areas with an important urban area typically exhibited high pollen richness. Low pollen richness was observed for apiaries located in the landscapes with important grassland or crop areas.

The Spearman test based on the entire landscape and palynological diversity data (Shannon indices) did not highlight a correlation between the landscape diversity and 
the pollen diversity $(\mathrm{p}>0.05 ; \mathrm{r}=-0.094)$. This result was illustrated by the foraging areas of apiaries $\mathrm{K}$ and $\mathrm{N}$, which were characterized by a low landscape diversity and high pollen diversity. However, apiary $\mathrm{G}$ presented high landscape and pollen diversities, as opposed to apiary $\mathrm{M}$, which was characterized by low landscape and pollen diversities.

The similarity indices were compared by a Mantel test (5000 randomizations). However, no correlation was demonstrated between the landscape data and pollen data $(\mathrm{p}>0.05 ; \mathrm{r}=0.1303)$.

CCA provided an overview of the land-cover data and the families identified in the pollen pellets and described the proximity between the variables and apiaries. The first factorial plane is displayed in Figure 5.

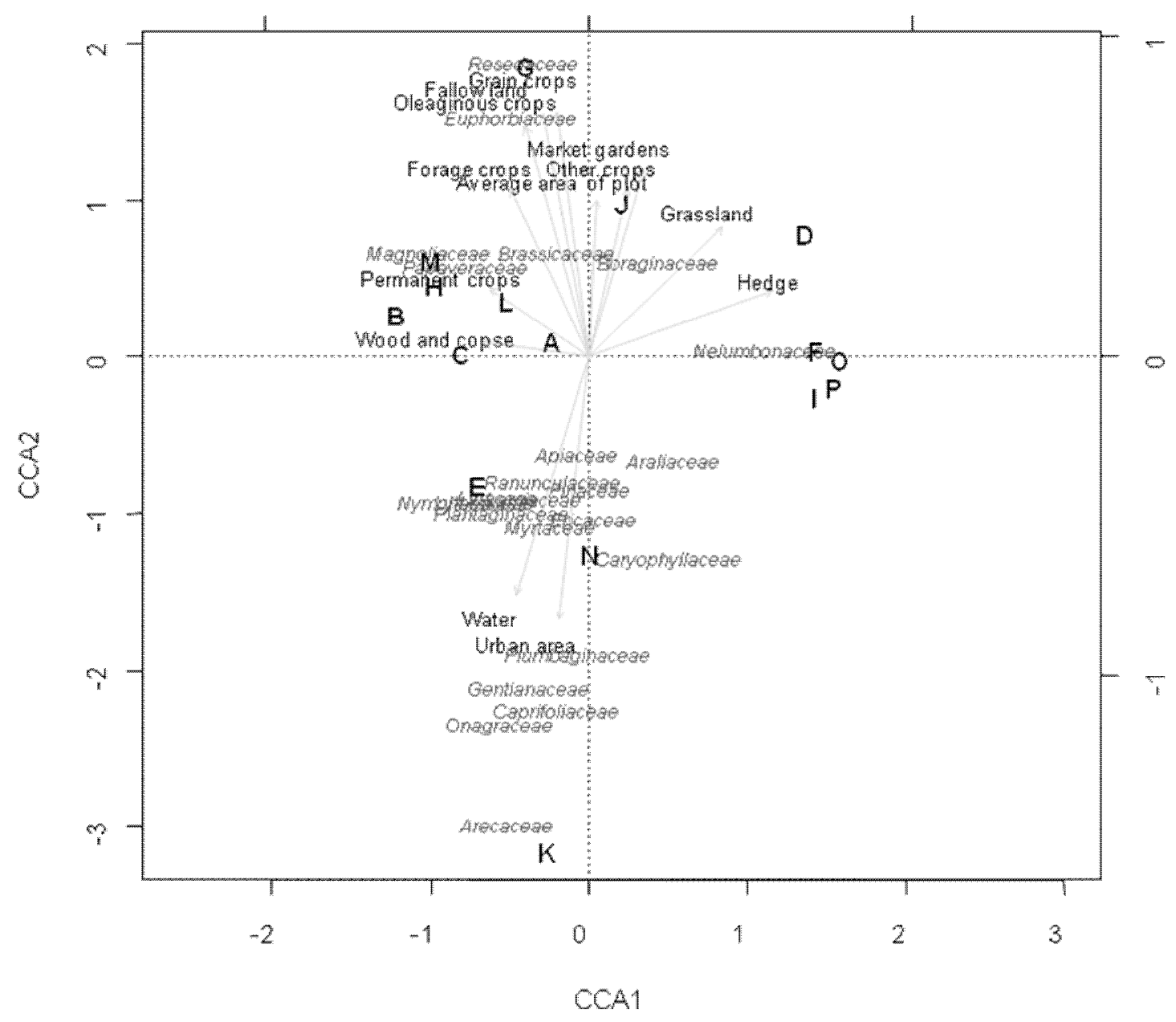

Figure 5. Projections of the variables (landscape and pollen data) and the apiaries on the first factorial plane of CCA (the species variables placed near the center of plot were removed for better readability).

The first CCA axis (CCA1, Figure 5) accounted for 31.16\% of the total inertia and revealed an opposition between the combination of the variables hedge, grassland and Boraginaceae and Nelumbonaceae and the combination of the variables permanent crops, oleaginous crops, grain crops, forage crops, fallow land and Magnoliaceae, Papaveraceae, and Brassicaceae. On the second axis, we have on one side the foraging 
areas $\mathrm{D}, \mathrm{F}, \mathrm{O}, \mathrm{P}$, and I (characterized by grassland, hedge, and their associated families) and on the other side the apiaries B, H, M, C, L, A, J, and G (characterized by crops and the associated families).

The second CCA axis (CCA2, Figure 5) accounted for $20.23 \%$ of the total inertia and revealed a combination of variables, including urban area, water, and Arecaceae, Onagraceae, Caprifoliaceae, Gentianaceae, and Plumbaginaceae. Additionally, on this axis in Figure 5, an opposition between apiaries $\mathrm{K}, \mathrm{N}$, and $\mathrm{E}$, characterized by urban area and their associated families, and the other apiaries is observed.

Many species (not represented on the graph) were not discriminative, such as Rosaceae, Asteraceae, Fagaceae, Poaceae, and Fabaceae.

\section{Discussion}

The different foraging areas were not classifiable into obvious landscape categories. The analysis revealed gradients of hedgerow density and variable proportion of grassland and crop areas. This result was because the apiaries were located in the same geographic region (western France), with a plain topography and comparable agricultural management, as characterized by a hedgerow landscape with mixed farming, in which pasture and permanent crops are present at different levels for each site (Burel and Baudry, 1990).

The land-cover data and similarity index (Bray-Curtis index) distinguished three groups of landscape contexts. The K, N, E, P, and C apiaries were characterized by an important urban area and a low crop area and were considered to be urban landscape. The other foraging areas were characterized by rural areas.

Our results demonstrated two groups of foraging apiaries within the rural landscape context according to the gradient of hedgerow networks and to the gradient of grassland and crop areas. Apiaries A, F, I, M, and $\mathrm{O}$ were defined by 1)a high length of hedges between 59 and $87 \mathrm{~m} / \mathrm{ha}$ and 2) numerous grassland plots comprising between $49 \%$ and $58 \%$ of the grassland and annual crop areas (32\% and $46 \%$ of the foraging areas), respectively. The landscape context for these apiaries would be close to a hedgerow landscape as defined by Michel et al. (2007) for western France. A second group including apiaries B, G, J, and L consisted of 1) a low hedgerow network between 17 and $35 \mathrm{~m} /$ ha and 2) large plots of crops, with an overall area comprising between $62 \%$ and $80 \%$ of the grassland and annual crop areas (45\% and $56 \%$ of the foraging areas), respectively. This group was characteristic of a cultivated landscape (Michel et al., 2007). Two apiaries (D and H) displayed intermediate values with important hedge lengths and crop plots, and exhibited difficulty with regard to classification within the landscape context of the foraging area.

\section{Landscape and flower diversity}

The land-cover data analyses indicated that the landscape richness was highest for the foraging areas of apiaries $\mathrm{B}, \mathrm{G}$, and $\mathrm{J}$ and was lowest for the $\mathrm{K}, \mathrm{M}, \mathrm{N}$, and $\mathrm{P}$ sites. The palynological analyses demonstrated that the pollen richness was more important for apiaries $\mathrm{K}$ and $\mathrm{C}$, whereas apiaries $\mathrm{F}$ and $\mathrm{M}$ displayed the lowest values. However, important landscape richness was not necessarily correlated with important pollen family richness and vice versa, as observed for apiaries $\mathrm{K}$ and $\mathrm{G}$. The foraging areas with important urban areas were sites that were characterized by a low landscape richness and a high pollen richness, which was linked to the flower 
diversity in the urban areas comprising many ornamental, cultivated and wild species (Dana et al., 2002; Acar et al., 2007; Hennig and Ghazoul, 2012). Accordingly, the pollen richness appeared less important for the apiaries surrounded by large crop and grassland areas. This finding might be explained by 1) the presence of species or varieties of the same species providing less attractive pollen (Louveaux, 1959; Pierre et al., 1999) and 2) chemical or mechanical management of the areas, reducing flower diversity and availability (Louveaux, 1959; Freemark and Boutin, 1995; De Snoo and van der Poll, 1999; Schippers and Joenje, 2002). In fact, Freemark and Boutin (1995) demonstrated that use of herbicides decreases the presence of self-propagating plants that could be attractive to honey bees (Louveaux, 1959). Intensive grazing, cutting prior to the flowering period, and fertilizer application have similar a negative impacts on flower richness (Schippers and Joenje, 2002).

Richness was associated with the different land-cover categories present in foraging areas and the different families of plant identified in the pollen. In addition to qualitative data, the diversity index takes into account quantity of the different variables. Additionally, apiary $\mathrm{C}$, which showed high pollen richness, had low pollen diversity. Conversely, apiary $\mathrm{G}$ had low pollen richness and high pollen diversity. Overall, the diversity was more noteworthy that the quality and quantity of data combined. There was no correlation between landscape diversity and pollen diversity, a result that can be illustrated by the foraging areas of apiaries $\mathrm{K}$ and $\mathrm{N}$, which were characterized by low landscape diversity and high pollen diversity. However, apiary G presented high landscape and pollen diversities, different from apiary $M$, which was characterized by low landscape and pollen diversities. These results can be explained this by the same reasons cited above.

The palynological analyses showed that the flower richness is greater in apiaries of urban landscapes than in apiaries of rural landscapes. Nevertheless, the diversity of pollen gathered by honey bees does not reflect the diversity of the landscape, which, in turn, depends on the landscape context (composition and structure) and management of the environment.

\section{Landscape and typical flora}

The similarity indices between the apiaries considering land-cover data were different from the similarity indices between the apiaries considering pollen data. Indeed the comparison of these similarity indices (the Mantel test) showed an absence of correlation. Thus, the apiary clusters built using palynological data were different from the apiary clusters built using land-cover data.

CCA permitted an overview of the land-cover and pollen data and a description of the proximity between the variables and apiaries. As was the case for the richness data, we observed an opposite trend between the urban landscape and rural landscape. The plant families associated with the pollen collected from urban areas were Arecaceae, Onagraceae, and Caprifoliaceae, and were mainly ornamental species present in parks and gardens. Although in low quantity, many ornamental species were present in parks and gardens, which partially explains the high flower richness but not necessarily the high flower diversity in the urban landscape. The foraging areas $\mathrm{K}, \mathrm{N}$ and $\mathrm{E}$, classified as urban landscapes, were characterized by these variables.

In the rural landscape, the apiaries were characterized by crops and three plant families: Magnoliaceae, an ornamental species well represented in this region, 
Papaveraceae, self-propagating plants mainly found in crops, and Brassicaceae, species widely cultivated in France.

Many wild, cultivated, and ornamental species were not found to be discriminating with regard to the landscape context, including Rosaceae, Asteraceae, and Fabaceae. These families are known for their high attractiveness to pollinators (Louveaux, 1958) and constituted the majority of the pollen identified. This concept of a main pollen source was introduced early in the study of palynology and is linked to the fact that honey bees select plants for the specific nutritional properties of their pollen (Louveaux, 1958; Hügel, 1962). This nutritional aspect most likely explains why pollen from the same families (main pollen), such as Asteraceae, Fabaceae, and Rosaceae, were reported to be selected and returned to hives in many countries, including France, the United States, and Brazil (Louveaux, 1959; Almeida-Muradian et al., 2005; Tuell et al., 2008; Boff et al., 2011).

In the rural landscapes, the pollen gathered by the honey bees was a not typical for many potential reasons: 1) the foraging areas were not homogeneous and included a mixture of grasslands, crops, market gardens, and urban areas (Burel and Baudry, 1990); 2) the pollen was sampled four times during the year and reflected a single time point, which may explain the omission of some families; 3) the palynological analyses were performed at the taxonomic level of the family and not at the species level; and 4) selective honey bee foraging is linked to pollen quality (Louveaux, 1958; Hügel, 1962; Blütghen and Klein, 2011).

Finally, Louveaux (1959) found a good correlation between land-cover, plant and pollen and considered honey bees as good investigative agent for botanical geography. However, this correlation was far from evident based on the analysis developed in the present study, as the results failed to relate a typical flora (notably flowers visited by honey bees) to a landscape context. Some explanations might include the following features: 1) our sampling method at a single time point did not reflect the dynamic pool of pollen and the complete botanical diversity over a full apicultural season; 2) our study concerned one geographical region with weakly differentiated landscapes compared to the Louveaux study performed over the entire country; and 3) many modifications in landscape structure, composition and management have occurred since the 1950s. However, our results did distinguish an urban landscape from a rural landscape based on the pollen gathered by honey bees and the dominance of ornamental species in the pollen gathered by the honey bees guides the characterization of the landscape as an urban landscape. Regardless, the scarcity or absence of ornamental species does not necessarily mean that the apiary is not located in an urban area.

\section{Conclusion}

Based on our results, it is concluded that the diversity of collected pollen is a poor indicator to employ for landscape qualification: a high landscape diversity does not necessarily entail a wider variability in the pollen gathered by honey bees. As a rule, the colonies were found to gather pollen that was not typical of the landscape defined for the apiary. The dominance of pollen from ornamental flowers may, however, have resulted in the characterization of a landscape as an urban landscape. In contrast, rural landscapes could not be discriminated by the pollen collected because honey bees presumably select pollen and favor flowers of nutritional interest. Therefore we suggest that although there is a dependency on the apiary environment and landscape context, 
the diversity of collected pollen is significantly influenced by additional factors, such as site management and selective foraging.

Acknowledgements. We thank all the beekeepers for their hospitality and their help with the protocol. Many thanks are extended to the regional delegation of the Ministry of Agriculture, in particular, Virginie Perin, for providing some of land-cover data.

We are grateful to Isabelle Guilberteau, Bénédicte Pouleur and Jean-Michel Allard from ONIRIS for the field sampling. We thank Romain Caseteuble for his work on these analyses. We also wish to thank all the sponsors.

This study was supported by the European Union trough European Agricultural Guidance Guarantee Fund projects, Nantes Métropole, le Conseil Général de Loire Atlantique, la Région des Pays de la Loire, and Pullman hotels by Bee my Friend.

\section{REFERENCES}

[1] Acar, C., Acar, H., Eroğlu, E. (2007): Evaluation of ornamental plant resources to urban biodiversity and cultural changing: a case study of residential landscapes in Trabzon city (Turkey). - Building and Environment 42: 218-229.

[2] Agger, P., Brandt, J. (1988): Dynamics of small biotopes in Danish agricultural landscapes. - Landscapes Ecology 1: 227-240.

[3] Alaux, C., Ducloz, F., Crauser, D., Le Conte, Y. (2010): Diet effects on honey bee immunocompetence. - Biology Letters 6: 562-565.

[4] Almeida-Muradian, L.B., Pamplona, L.C., Coimbra, S., Barth, O.M. (2005): Chemical composition and botanical evaluation of dried bee pollen pellets. - Journal of Food Composition and Analysis 18: 105-111.

[5] Balayiannis, G., Balayiannis P. (2008): Bee honey as an environmental bioindicator of pesticides' occurrence in six agricultural areas of Greece. - Archives of Environmental Contamination and Toxicology 55: 462-470.

[6] Beekman, M., Ratnieks, F.L.W. (2000): Long-range foraging by the honey-bee, Apis mellifera L.. - Functional Ecology 14: 490-496.

[7] Benton, T.G., Vickery, J.A., Wilson, J.D. (2003): Farmland biodiversity: is habitat heterogeneity the key? - Trends in Ecology and Evolution 18: 182-188.

[8] Blüthgen, N., Klein, A.M. (2011): Functionnal complementarity and specialization: the role of biodiversity in plant-pollinator interactions. - Basic and applied ecology 12: 282-291.

[9] Boff, S., Luz, C.F.P., Araujo, A.C., Pott, A. (2011): Pollen Analysis Reveals Plants Foraged by Africanized Honey bees in the Southern Pantanal, Brazil. - $\quad$ Neotropical Entomology 40: 47-54.

[10] Burel, F., Baudry, J., (1990): Structural dynamic of a hedgerow network landscape in Brittany France. - Landscape Ecology 4: 197-210.

[11] Burel, F., Baudry, J. (1999): Des paysages passés aux paysages anthropisés actuels. - In: Lavoisier (Editions Tec \& Doc) Ecologie du paysage Concepts, méthodes et applications, Paris.

[12] Carvell, C., Meek, W.R., Pywell, R.F., Goulson, D., Nowakowski, M. (2007): Comparing the efficacy of agri-environment schemes to enhance bumble bee abundance and diversity on arable field margins. - Journal of Applied Ecology 44: 29-40.

[13] Crailsheim, K., Schneider, L.H.W., Hrassnigg, N., Bühlmann, G., Brosch, U., Gmeinbauer, R., Schöffmann, B. (1992): Pollen consumption and utilization in worker honey bees (Apis mellifera Carnica): dependence on individual age and function. Journal of Insect Physiology 38: 409-419.

[14] Dana, E.D., Vivas, S., Mota, J.F. (2002): Urban vegetation of Almería City-a contribution to urban ecology in Spain. - Landscape and Urban Planning 59: 203-216. 
[15] De Snoo, G.R., van der Poll, R.J. (1999): Effect of herbicide drift on adjacent boundary vegetation. - Agriculture, Ecosystem and Environment 73: 1-6.

[16] Freemark, K., Boutin, C. (1995): Impacts of agricultural herbicide use on terrestrial wildlife in temperate landscapes: a review with special reference to North America. Agriculture Ecosystem and Environment 52: 67-91.

[17] Gonzalez, I., Déjean, S., Martin, P.G.P., Baccini, A. (2008): CCA: an R package to extend canonical correlation analysis. - Journal of Statistical Software 23: 1- 14.

[18] Hadley, A.S., Betts, M.G. (2012): The effects of landscape fragmentation on pollination dynamics: absence of evidence not evidence of absence. - Biological reviews 87: 526544.

[19] Hannon, L.E., Sisk, T.D. (2009): Hedgerows in an agri-natural landscape: Potential habitat value for native bees. - Biological Conservation 142: 2140- 2154.

[20] Hennig, E.I., Ghazoul, J. (2012): Pollinating animals in the urban environment. - Urban ecosystem 15: 149-166.

[21] Hobbs, N.T., Galvin, K.A., Stokes, C.J., Lackett, J.M., Ash, A.J., Boone, R.B., $\quad$ Reid, R.S., Thornton, P.K. (2008): Fragmentation of rangelands: Implications for humans, animals, and landscapes. - Global Environmental Change 18: 776- 785.

[22] Holzschuh, A., Steffan-Dewenter, I., Kleijn, D. and Tscharntke, T. (2007): Diversity of flower-visiting bees in cereal fields: effects of farming system, landscape composition and regional context. - Journal of Applied Ecology 44: 41-49.

[23] Hügel, M.F. (1962): Etudes de quelques constituants du pollen. In: Annales de l'abeille.

[24] Krebs, J.R., Wilson, J.D., Bradbury, R.B., Siriwardena, G.M. (1999): The second silent spring. - Nature 400: 611-612.

[25] Lambert, O., Piroux, M., Puyo, S., Thorin, C., Larhantec, M., Delbac, F., Pouliquen, H. (2012): Bees, honey and pollen as sentinels for lead environmental contamination. Environmental pollution 170: 254-259.

[26] Le Féon, V., Schermann-Legionnet, A., Delettre, Y., Aviron, S., Billeter, R., Bugter, R., Hendrickx, F., Burel, F. (2010): Intensification of agriculture, landscape composition and wild bee communities: A large scale study in four European countries. Agriculture, Ecosystems and Environment 137: 143-150.

[27] Loibl, W., Toetzer, T. (2002): Modeling growth and densification processes in suburban Regions - simulation of landscape transition with spatial agents. - Environmental Modelling \& Software 18: 553-563.

[28] Louveaux, J. (1958): Plantes utilisées par les abeilles. In: Annales de l'Abeille, Recherches sur la récolte du pollen par les abeilles (Apis mellifica L.).

[29] Louveaux, J. (1959): Recherches sur l'origine des variations qualitatives. In: Annale de l'Abeille, Recherches sur la récolte du pollen par les abeilles (Apis mellifica L.)

[30] Macdonald, D.W., Johnson, P.J. (2000): Farmers and the custody of the countryside: trends in loss and conservation of non-productive habitats 1981-1998. - Biological Conservation 94: 221-234.

[31] McLaughlin, A., Mineau, P. (1995): The impact of agricultural practices on biodiversity. - Agriculture Ecosystem and Environment 55: 201-212.

[32] Michel, N., Burel, F., Legendre, P., Butet, A. (2007): Role of habitat and landscape in structuring small mammal assemblages in hedgerow networks of contrasted farming landscapes in Brittany, France. - Landscape Ecology 22: 1241-1253.

[33] Monteiro, A.T., Fava, F., Hiltbrunner, E., Della Marianna, G., Bocchi, S. (2011): Assessment of land cover changes and spatial drivers behind loss of permanent meadows in the lowlands of Italian Alps. - Landscape and Urban Planning 100: 287-294.

[34] Perugini, M., Di Serafino, G., Giacomelli, A., Medrzyck, P., Sabatini, A.G., Persano Oddo, L, Marinelli, E., Amorena, M. (2009): Monitoring of polycyclic aromatic hydrocarbons in bees (Apis mellifera) and honey in urban areas and wildlife reserves. Journal of Agricultural Food and Chemistry 57: 7440-7444. 
[35] Pierre, J., Mesquida, J., Marilleau, R., Pham-Délègue, M.H., Renard, M. (1999): Nectar secretion in winter oilseed rape, Brassica napus - quantitative and qualitative variability among 71 genotypes. - Plant Breeding 118: 471-476.

[36] Potts, S.G., Biesmeijer, J.C., Kremen, C., Neumann, P., Schweiger, O., Kunin, W.E. (2010): Global pollinator declines: trends, impacts and drivers. - Trends in ecology and evolution 25: 345-353.

[37] Robinson, R.A., Sutherlend, W.J. (2002): Post-war changes in arable farming and biodiversity in Great Britain. - Journal of Applied Ecology 39: 157-176.

[38] Schippers, P., Joenje, W. (2002): Modelling the effect of fertiliser, mowing, disturbance and width on the biodiversity of plant communities of field boundaries. Agriculture, Ecosystems and Environment 93: 351-365.

[39] Steffan-Dewenter, I., Münzenberg, U., Bürger, C., Thies, C., Tscharntke, T. (2002): Scale-dependent effects of landscape structure on the three pollinators guilds. - Ecology 83: $1421-1432$.

[40] Steffan-Dewenter, I., Kuhn, A. (2003): Honey bee foraging in differentially structured landscapes. - Proceedings of the Royal Society B. 270: 569-575.

[41] Ter Braak, C.J.F., Verdonschot, P.F.M. (1995): Canonical correspondence analysis and related multivariate methods in aquatic ecology. - Aquatic Sciences $\quad$ 57: 255-289.

[42] Tuell, J.K., Fiedler, A.K., Landis, D., Isaacs, R. (2008): Visitation by Wild and Managed Bees (Hymenoptera: Apoidea) to Eastern U.S. Native Plants for Use in Conservation Programs. - Environmental Entomology 37: 707-718.

[43] Visscher, P.K., Crailsheim, K., Sherman, G. (1996): How do honey bees (Apis mellifera) fuel their water foraging flights? - Journal Insect Physiology 42: 1089-1094.

[44] Von der Ohe, W., Persano Oddo, L., Piana, M.L., Morlot, M., Martin, P. (2004): Harmonized methods of melissopalynology. - Apidologie 35: S18-S25.

[45] R: A language and environment for statistical computing. R Foundation for Statistical Computing, Vienna, Austria. ISBN 3-900051-07-0, URL http://www.R-project.org.)

\section{Appendices}

Appendix A. Detailed description of the variables used in the study (* Declarative data for 2008 of the agricultural parcel identification system of Council Regulation (EC) $N^{\circ}$ 1593/2000 of 17 July 2000).

\begin{tabular}{|c|c|c|c|}
\hline Variables & Description & Sources & Units \\
\hline Grassland & natural meadows, temporary meadows & $*(\mathrm{PN}, \mathrm{PT}, \mathrm{PX})$ & ha \\
\hline Fallow land & fallow land & $*(\mathrm{GE}, \mathrm{GB}, \mathrm{GI}, \mathrm{GV})$ & ha \\
\hline Forage crops & forage, broad bean, pea & $*(\mathrm{DH}, \mathrm{FA}, \mathrm{FE}, \mathrm{GL}, \mathrm{LP}, \mathrm{PH}, \mathrm{PP}, \mathrm{SM})$ & ha \\
\hline Grain crops & oat, wheat, maize, barley, rye & $\begin{array}{l}*(\mathrm{AC}, \mathrm{AV}, \mathrm{BA}, \mathrm{BB}, \mathrm{BD}, \mathrm{BH}, \mathrm{BP}, \mathrm{BT}, \mathrm{MA} \\
\mathrm{MD}, \mathrm{ME}, \mathrm{MS}, \mathrm{OH}, \mathrm{OP}, \mathrm{SE}, \mathrm{SH}, \mathrm{TR})\end{array}$ & ha \\
\hline Oleaginous crops & colza, flax, sunflower & $*(\mathrm{AO}, \mathrm{CH}, \mathrm{LN}, \mathrm{LU}, \mathrm{TO})$ & ha \\
\hline Permanent crops & vineyard, orchard & $*(\mathrm{VE}, \mathrm{VI})$ & ha \\
\hline Market gardens & fruit, vegetable, aromatic plant & $*(\mathrm{FP}, \mathrm{LC}, \mathrm{PE}, \mathrm{PF}, \mathrm{PM}, \mathrm{PO})$ & ha \\
\hline Other crops & buckwheat, hemp, tobacco & $*(\mathrm{AT}, \mathrm{CU}, \mathrm{CV}, \mathrm{CW}, \mathrm{SR}, \mathrm{TA})$ & ha \\
\hline Wood and copse & & $\begin{array}{l}\text { Corine Land Cover } 2006 \text { (31.1/31.2/31.3) } \\
\text { Digitized on BD ORTHO ® IGN (2004) }\end{array}$ & ha \\
\hline
\end{tabular}




\begin{tabular}{l|l|l|c} 
Urban area & urban infrastructure, airport & $\begin{array}{l}\text { Corine Land Cover } 2006 \\
(11.1 / 11.2 / 12.1 / 12.2 / 12.3 / 12.4) \\
\text { Water }\end{array}$ & Corine Land Cover 2006 (51.1/51.2) \\
Others & $\begin{array}{l}\text { other utilization declared, no agricultural } \\
\text { use, area not determined }\end{array}$ & *(AU, HC, UN) & ha \\
Hedge & Digitized on BD ORTHO \& IGN (2004) & ha \\
Average plot size & Field survey among farmers in the foraging area & ha \\
\hline
\end{tabular}

